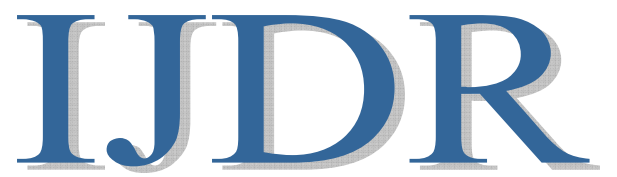

International Journal of Development Research

Vol. 10, Issue, 06, pp. 36562-36567, June, 2020

https://doi.org/10.37118/ijdr.19012.06.2020

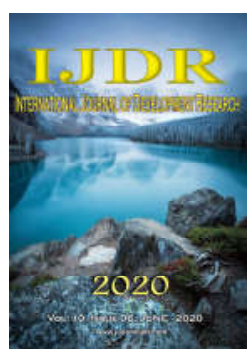

\title{
USE OF AEROGENERATORS FOR ALTERNATIVE ELECTRICITY PRODUCTION: ADAPTATIONS AND CHALLENGES IN MANAUS COMPANY
}

\section{Ewerthon Juliano da Silva Herculano, ${ }^{1}$ Márcio Figueiredo Moraes, ${ }^{1}$ Livia da Silva Oliveira, 1Suelânia Cristina Gonzaga de Figueiredo and ${ }^{* 2}$ David Barbosa de Alencar}

\author{
${ }^{1}$ Academic department, University Center FAMETRO, Amazon-Brazil \\ 2Institute of Technology and Education Galileo of Amazon (ITEGAM), Brazil
}

\section{ARTICLE INFO}

Article History:

Received $03^{\text {rd }}$ March, 2020

Received in revised form

$17^{\text {th }}$ April, 2020

Accepted $06^{\text {th }}$ May, 2020

Published online $25^{\text {th }}$ June, 2020

\section{Key words:}

Wind turbines, Energy, Sustainability, utilization, self-sufficient.

\author{
*Corresponding author: \\ Ewerthon Juliano da Silva Herculano
}

\begin{abstract}
The combination of tools and the possibility of arranging mechanisms that prove to be sustainable and aimed at meeting a certain environmentally correct demand is a challenge today, as it depends on the perception of professionals in charge of implementing changes in conventional systems. Ensuring that the precepts of energy production are shaped bringing more efficiency, also implies the impact on the environment, be it small, medium or large, certainly, that actions that reduce this impact corroborate for new conducts and other applications. An aerogenerator system is a device capable of generating energy by the force of the winds, which mobilizes the blades, whose movement can be reused to aerate environments. What brings the expectation of the speed gain generated in the blades of the system, can be passive of other uses, this aspect can turn into advantages, because these subsidies would be wasted if they were used independently they would be wasted. This work is part of a construction of a system implanted in a factory in the Industrial District of Manaus, using a 500 Watt wind turbine for power generation, where the system was adapted to an extractor in the factory's Cafeteria for presenting a slab that facilitated the installation. The idealization of a combination of instruments that will compose a matrix capable of acting with sustainability, the methodology consists of creating a mechanism of reordering a structure to maintain itself with sustainability, with a bibliographic survey on the impact conditions of the use of materials for power generation, combining fundamentals for the application of the generated by-products.
\end{abstract}

Copyright $@$ 2020, Ewerthon Juliano da Silva Herculano et al. This is an open access article distributed under the Creative Commons Attribution License, which permits unrestricted use, distribution, and reproduction in any medium, provided the original work is properly cited.

Citation: Ewerthon Juliano da Silva Herculano, Márcio Figueiredo Moraes, Livia da Silva Oliveira, Suelânia Cristina Gonzaga de Figueiredo and

David Barbosa de Alencar. "Use of aerogenerators for alternative electricity production: adaptations and challenges in manaus company", International Journal of Development Research, 10, 06, 36562-36567.

\section{INTRODUCTION}

The use of natural resources is an aspect that is in evidence in society today. Much is speculated about the configurations of sustainable energy production in relation to the impacts they cause by the use of new materials that are available and able to be retrofitted in intelligent systems. For this to happen, it is necessary for professionals in the technological areas to be concerned with finding solutions to diversify applications and, above all, to combine resources to minimize impacts on the environment. Data published by Braskem (2019) - National Electric Energy Agency - highlights that in Brazil the potential of wind energy corresponds to $9.2 \%$, biomass to $9 \%$, natural gas $(8.1 \%)$, oil $(5,4 \%)$, mineral coal $(2 \%)$, photovoltaic energy $(1.3 \%)$ and nuclear energy $(1.2 \%)$.
These data indicate that the diversity of options for producing energy from sustainable sources, expands over the years with the possibility of new implementations, this increases diversification, making it possible to reduce the dependence on hydroelectric energy that stands out within the national scenario, due to the abundance of water. The energy from the wind (wind) is a sustainable form and to obtain it it is necessary to use an wind turbine that consists of an electricity generator added to the axis of a vane, capable of converting mechanical energy into electrical energy. This mechanism is integrated with a system of propellers (blades) that activate the mechanism and make the device work generating electricity. Data that reveal the utility of wind energy and state that this type of power generation source, worldwide, reached a capacity of 600GW in 2018 (ENERCONS, 2019). 
The perspective is that this type of power may have its expansion due to the characteristic of solving technical problems with generation materials, including wind turbines. China is the world leader because it holds one third of the world capacity, Gansu Province, the largest wind farm on Earth - Installed capacity 7,965 MW, is an example of the gradual use of this form of energy (ENERCONS, 2019). The leadership in the use of wind energy continues with the USA with 96.4GW, Germany 59.3GW, India 35GW, Spain $23 \mathrm{GW}$, United Kingdom 20.7 GW, France 15.3GW and Brazil with $14.5 \mathrm{GW}$ which is located ahead of Canada with $12.8 \mathrm{GW}$, Italy with $10.1 \mathrm{GW}$ (ENERCONS, 2019). It is observed that Brazil has a privileged capacity for the production of wind energy, as it has a very favorable coastal strip for the use of the winds and in the list above does not highlight any country in South America, which puts it prominently in the face of the great potential of the area with the possibility of expansion.

The possibility of energy production by the force of winds in an open environment in Brazil is expanding with massive investments and embedded technology, but it is possible to reconcile for systems adapted for the application of winds from activities that produce wind by dissipation. This proposal brings a study of the location of a $500 \mathrm{~W}$ wind turbine installed in a factory in the Industrial District of Manaus, using the winds from an exhaust fan in the company's cafeteria for presenting desirable conditions for its implementation. The system was duly planned and executed for the production of clean and alternative energy, using low-cost equipment and production of sufficient energy for use in other systems, including in the absence of conventional energy to satisfy the existing demand. As it is an energy production mechanism with an alternative feature, several forms of use have been planned, as the idea is to diversify the use, as in this case, in order to avoid voltage loss, a system mechanism was designed that was activated when the conventional network produces oscillation or functional intermittency. For this work, the intention is not only the production of energy that is in focus, but the ability to impact the environment, with the perspective of using, or reusing, by-products generated by manufacturing activities, for the application of such potentials in function of the power generating capacity through intelligent mechanisms, the use of the extractor is shown as a way of using the winds from the work system such as electroplating and other processes that enable the production of electrical energy from the strength of the winds, this energy with characteristic clean and sustainable can be used in other forms of use, configuring an alternative way of obtaining and using existing resources. One can also think about the use of waste water for cleaning solar panels, cleaning product residues and others that impact the environment, as in the case of the study highlighted here, due to the convenience of offering subsidies, as a by-product of an irrigation work activity. demands, these environmental demands imply impacts and these impacts can be minimized with corrective attitudes of use of residues such as wind, washing water and others, converting possible problems into adequate and sustainable resources.

\section{THEORETICAL FRAMEWORK}

Wind generator and its characteristics: According to Coutinho (2019) the wind turbine consists of the equipment responsible for transforming wind speeds into electrical energy, it has the property of being activated by the winds, and can be configured in various ways, depending on the need it can be adapted as a subsidy for improvement in energy quality, impact on the environment, as well as converting the energy of the wind movement (kinetic) into electrical energy. For the use of a wind turbine, it is necessary to know its composition, or at least, to identify the properties of the essential parts for its operation. According to Moraes (2019), the composition of a wind turbine is more understandable if three aspects are considered, such as the tower, the power train and the blades or propellers, among the most important points to be broken down, in the case of a system that works depending on the rotation and translation of the equipment. Faced with an operating system where movement is the differential factor in the system, its efficiency in the rotations of the $\mathrm{X}, \mathrm{Y}$ and $\mathrm{Z}$ axes can be evaluated, whose movement is balanced by the fixation in the nacelle located at the top of the tower. According to Moraes (2019) the movement that occurs on the $\mathrm{Z}$ axis has the name of camber or yaw (English: Yaw), whereas the rotation of the $\mathrm{X}$ axis is classified as scroll or list (English: roll) and the $\mathrm{Y}$ axis the name is tilt (from English: tilt), this whole set of factors responds to a system that is part of a plane corresponding to the rotor.

The choice of an aerogenerator for an application involves identifying the type of Rotor that is extremely important due to the condition of the rotating axes, since in operation the blades can oscillate their movement causing a change in behavior outside the rotor plane. The operating pattern of the device is understood that the movement frequencies of the blades are synchronized and if this synchronization begins to lose its stability and this tends to affect the performance of the wind turbine (MORAES, 2019. p. 37). The understanding of the wind turbine's functionality and the combination of factors that minimize deviations provide the device with the application differential, so the modeling and analysis of physical conditions foreseeing variations and minimizing contrary impacts can be triggered by simulations or experiments that are viable mechanisms to collaborate adjusting the system. Moraes (2019) highlights that the execution and detailing of an experimental methodology can be decisive for minimizing the vibrations of the blades, as it will allow to visualize the variations with measurements and fittings.

Wind turbines and the notions of aerodynamics: As the wind turbine is positioned on the wind path, the rotation system must be planned in order to achieve energy generation efficiency. The rotors (vertical axis) are a type of wind turbine that does not require the monitoring mechanism to change the wind direction, this condition allows the project to be simpler, they can be caused by lift and drag forces. Rotors (horizontal axis) are the most common and the most used due to their functionality. According to Neto (2018) the aerodynamic forces that move the rotors are known as lift and drag (drag) and a body that tends to obstruct the winds receives the movement and reproduces the action of the forces in the direction of flow, these forces provide the development of movement and depend on the formatting of the receiving body and the deviation of position to generate work with the speed of the winds. The rotors rotate by the lifting forces that make it possible to increase the power due to the drag forces, these rotors (horizontal axis) have mechanisms that allow the sweeping disk by the blades to be in a position perpendicular to the wind, this mechanism junction allows the aerodynamics of the device is balanced since the system contains one to three blades, and these blades must have different shapes and consist of suitable materials, such as cellulose (wood), aluminum (Al) 
or fiberglass (carbon) (NETO, 2018). The wind turbines can be observed and their construction follows standards that favor the aerodynamics of the device.

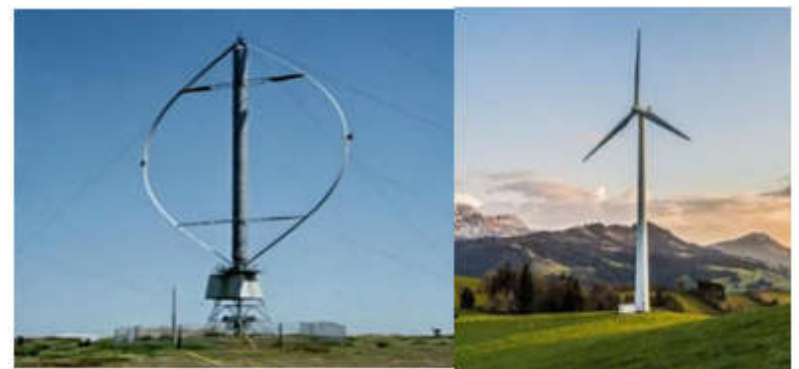

Source: Santos (2018) adapted.

Fig. 1: Wind turbine with vertical and horizontal axis rotor.

Figure 1 highlights a comparison of the different types of wind turbines, with vertical and horizontal axis. Within the construction of a wind turbine project, aerodynamics is most prominent in the understanding and level of performance of the device, being the field of fluid mechanics that studies the movement of air around the bodies. This allows the actions to be integrated to position an object to capture the resistance to the passage of air, it starts to describe a flat surface, arranged perpendicular to the direction of the winds, this mechanism undergoes a sharp resistance, in view of the collision of air with the structure, allowing the incidence of turbulence. Renewable sources are those that, due to their restoration in nature, are much faster in their energy use (the waters of rivers, tides, sun, winds) or management through the action of man can be carried out in combination with the needs of their energy use. (biomass: sugar cane, energy forests and animal, human and industrial waste). Most sources have statistical and stochastic properties, somewhat cyclical, in periods of time compatible with the operation of power plants and shorter than their useful life. Such sources can be used to produce electricity mainly through hydroelectric, wind, solarphotovoltaic and thermal power plants (Silva, 2019).

\section{MATERIALS AND METHODS}

For the location of the system, a system was planned that integrated the forms of alternative energy for that purpose, a survey of the situation about the characteristics of the forms of generation and their properties was carried out. Figure 2 highlights the survey layout of the guiding aspects for carrying out the research. The comparison of energy potentials and the probabilities of implantation in a closed environment aimed at harnessing the winds generated by the activity inside the factory cafeteria, the work improvement logistics passes to absorb an engineering methodology, according to FEBRACE (2016) o Engineering method - characterized in the process of change that results in the creation of goods, this list of options involves calculations, drawings and schemes performed by the engineering professional. For this purpose, the survey, the assimilation of needs and demands are required for the manufacture, availability and future disposal of the goods after the end of their useful life. In order to carry out the work, it is important to survey the characteristics of the problem, such as the definition of the causes and effects of the implementation, with the search for solutions to meet the need for a system of demands, embarking on the necessary requirements for the insertion of this system.

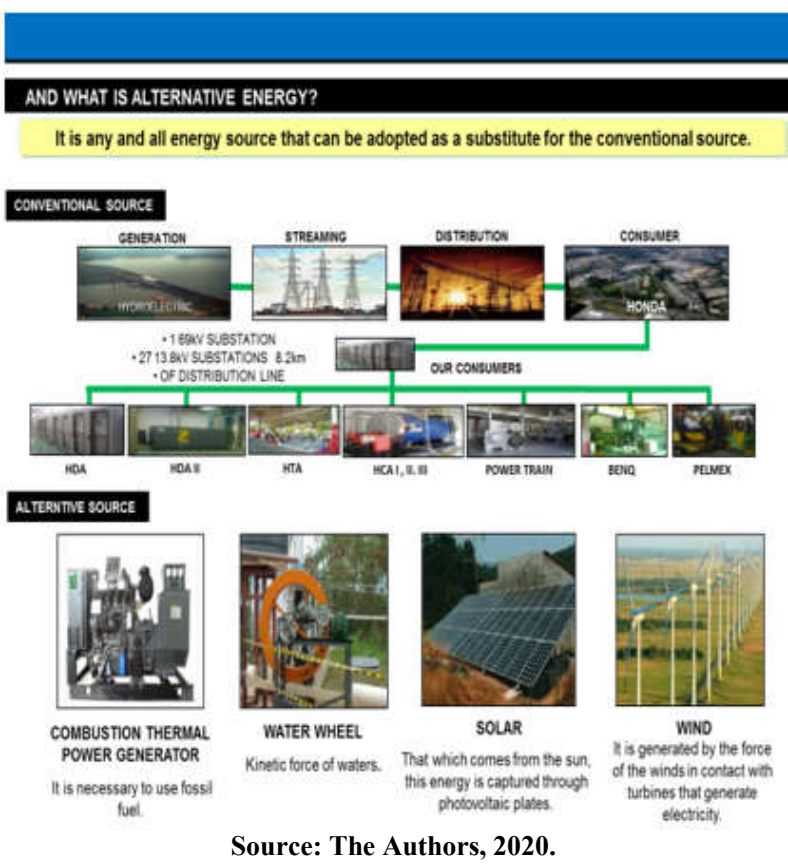

Fig. 2: Survey of operational study conditions for energy production.

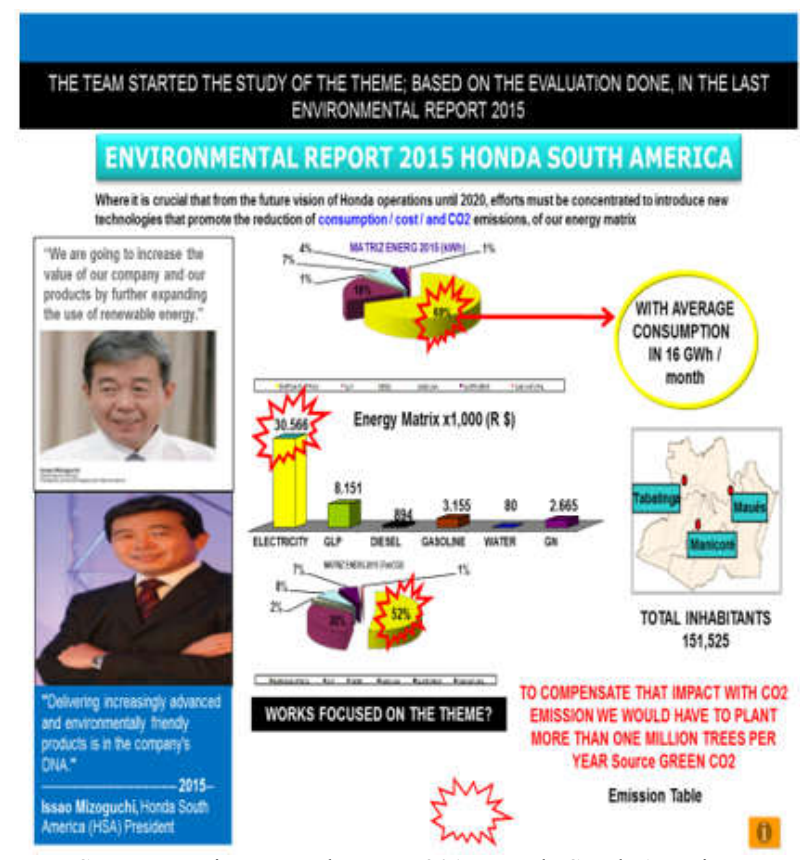

Source: Environmental Report 2015 Honda South America.

Fig. 3: Percussive factors of feasibility of studies and implementation.

Problem viewing and tabulating the results conditions if it was feasible or needs new reconsiderations.

The engineering method according to Cavalcante (2018) allows a methodical approach, requiring that successive steps be triggered that allows the problem and its complexity to be reconciled, bringing an analysis of the cognitive reconciling the experiences and technical planning to minimize errors, therefore, the strategy is to decrease the amount of errors and approximations to reconcile science, art, experience for energy generation. The application of the method occurs in an attractive way, as it can generate an innovation or evolution through the interactive environment and able to be arranged with technical solutions based on creativity and normative principles. 
In order to reconcile the method and the product that is expected to be achieved, the rearrangement options must be improved to activate the useful tools capable of grouping conditions of sustainability in the process.

\section{RESULTS AND DISCUSSION}

In view of what was estimated in the idealization of actions in the work plan where all stages were gradually carried out, by choosing the team, choosing the theme, surveying the current situation of energy sources, analyzing the causes and defining the solutions, where the results were obtained, which will be described below. As it started from an analysis of the situation of the energy production scenario and the impacts caused by the release of polluting gases into the atmosphere, figure 3 shows a projection of the factors that motivated the research and implementation of the system.

According to studies published in the 2015 Environmental Report in a view of the Honda group in South America, it was observed that many efforts have been made to insert new technologies in the production system with a view to reducing consumption, cost and emission of polluting gases, with a look at the energy matrix that improves in the presence of consumption. The way out of the profitability and balance of companies is to invest in renewable energies, since the abundance of inhabitants tends to increase and with that the energy expenditure too, for this reason making a search for a solution valuing the creative and adaptive capacity of professionals it is a condition that can bring combined solutions. For Boff (2017), renewable energies give an option to mitigate the negative impacts generated by the forms of generation from fossil sources, since their origin comes from natural cycles, this facilitates the use of these sources, said inexhaustible, to be beneficial for the planet as they can be produced with combined technologies, with low environmental impact and do not interfere with climate change.

Many international agreements are made to trigger the alert of the indiscriminate use of energy production sources that impact the environment, for this reason there is a race for the insertion of technologies that address this trend that minimizes environmental impacts. It is an insertion of a system that tends to take advantage of subsidies from a factory activity. Electricity was assessed through the DST cycle, which consists of imagining and drawing the ideal working condition, seeing reality through its nature of options. and consider what needs to be done. For this work, the working condition was estimated, seeing the maximum efficiency in the use of electric energy, basing costs and environmental impacts and to reduce costs, environmental impacts and the solution of using renewable electric energy as a counterpart, renewable energies was that preferred to address the theme "alternative energy generation".

Silva (2019) points out that alternative energy sources are those that are not generated by fossil fuels, being cleaner and do not impact the environment, it is important to note that not all alternative sources are renewable. It is important to remember that alternative energy production potentials can be combined with existing processes, such as, for example, byproducts of manufacturing processes that discard diversified inputs. Figure 4 presents an approach on alternative energy configurations, inserting the concept and the diversity of options that can be triggered by this chain of possibilities.

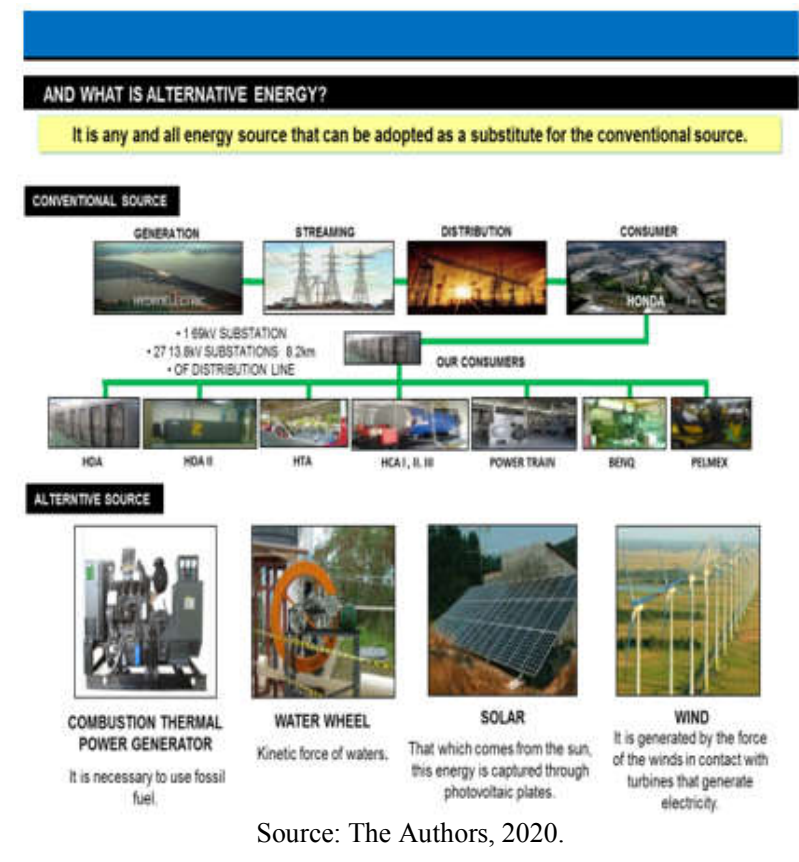

Fig. 4 : Alternative energies and their diversity of applications.

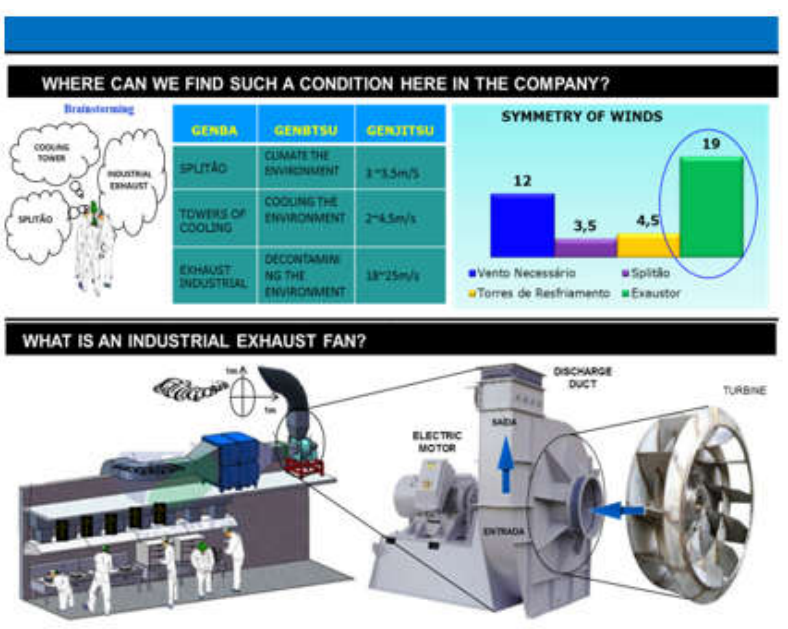

Source: The Authors, 2020.

Fig. 5. Factory environment with the possibility of installing the wind turbine

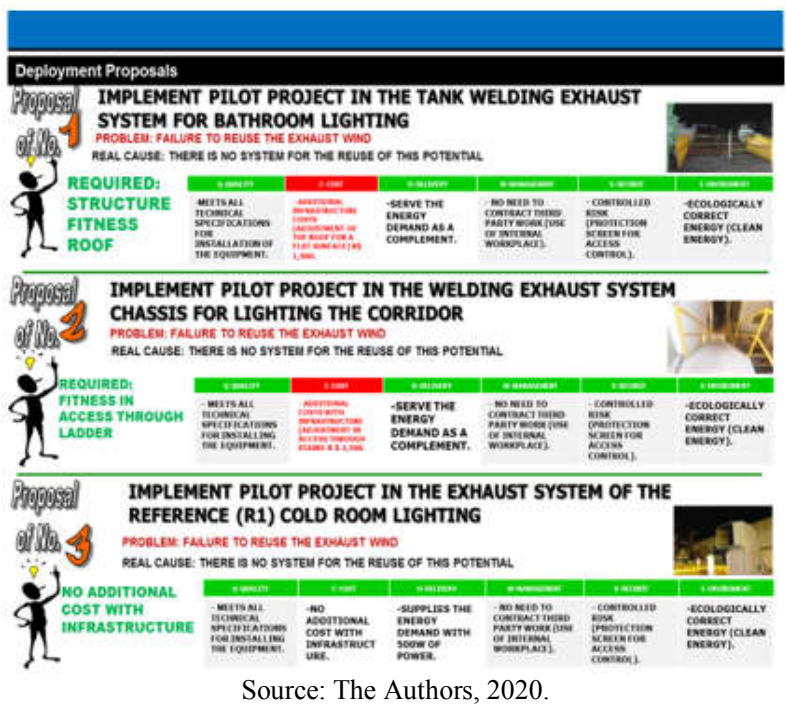

Fig. 6. Proposed systems for implementing the wind system project at the factory. 

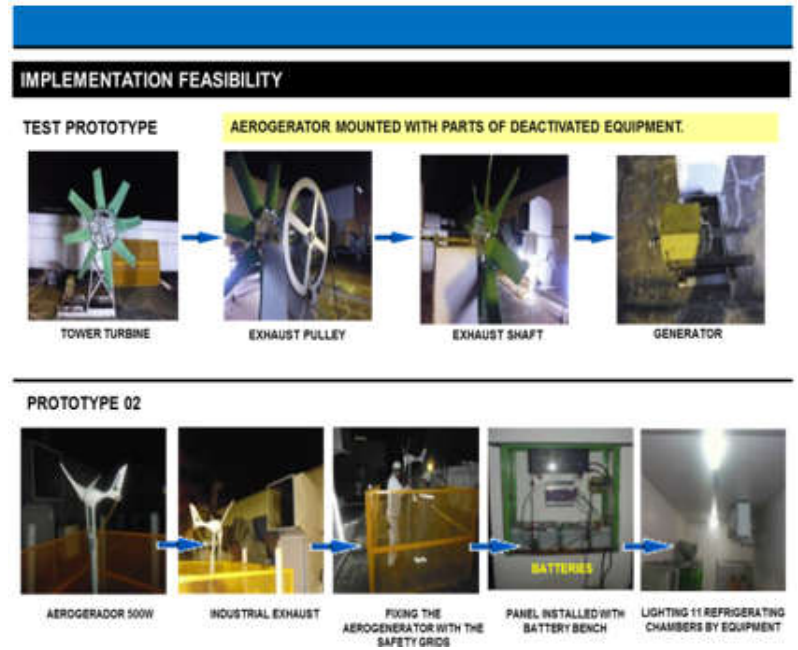

Source: The Authors, 2020

Fig. 7. Scheme of assembly of prototypes of implantation in the factory
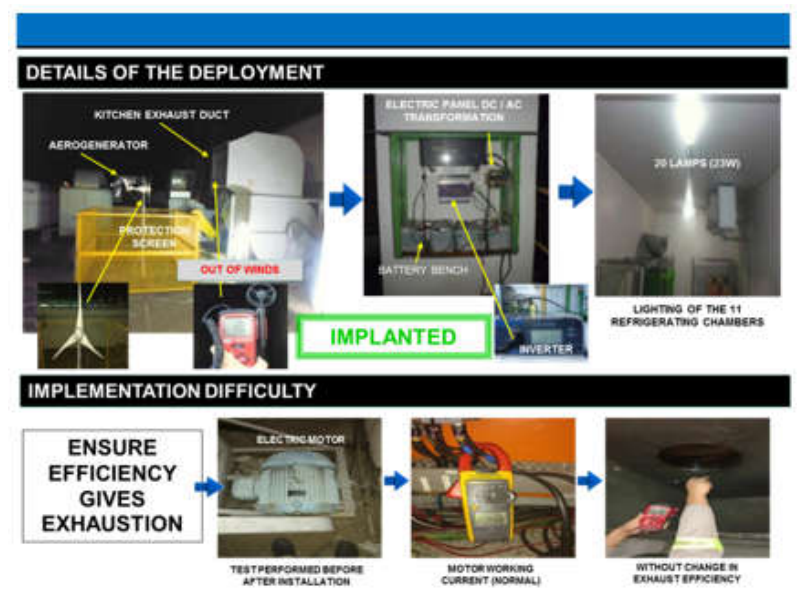

Source: The Authors, 2020

Fig. 8. Detailing the installation of the system in the factory environment

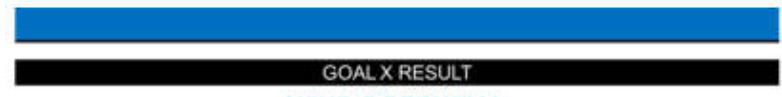

WIND POTENTIAL

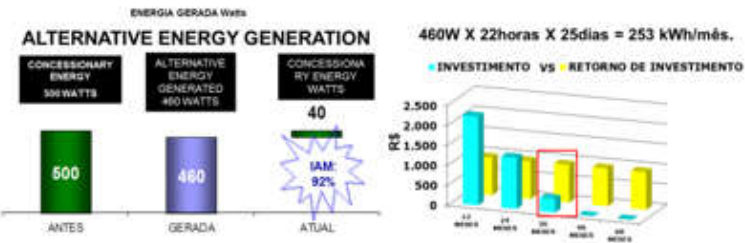

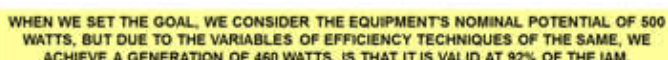

We also stopped emitting $377 \mathrm{KgCO} 2$ / year to the environment. Source: The Authors, 2020

Fig. 9. Demonstration of the efficiency of theinstalled wind system

Among the energy production options, wind was chosen because it presents favorable conditions within the possible environment of execution and for being adaptable to a specific situation. With this carried out the study of the suitability of the system for the rental of the wind turbine at the factory, figure 5 highlights a layout of the plant's functional system.
The capture of the wind generated by the extractor was attractive for the use and improvement of the insertion of the device, thus carrying out the feasibility study with analysis of power, speeds, air temperature and the qualification of the equipment whose model was implemented with the diameter the $205 \mathrm{~cm}$ rotor. As it is an application adapted to the allocation of materials and labor, it was described in a singleline diagram with the details and conditions of standards. As for the method used, the condition of the local ventilation was verified, being forced ventilation, it was not feasible to use the system as it was imagined, so how to generate alternative energy through the wind forces of industrial exhaust fans, the system is compromised by the related conditions. reusing existing potential. For the location of the pilot project in the exhaust fan of the HDA cafeteria, generating 500 watts of power, a system of wind potential was used for the rest of the plant, in this way the potential was measured by measuring the demand of the plant, which is estimated at 162 X18 hours X 24 days reaches a consumption of $69.984 \mathrm{kWh} /$ month and of the 54 hoods $\mathrm{x} 3 \mathrm{kWh}$ of $162 \mathrm{kWh}$. As can be seen, energy expenditure at the plant would be decisively impacted in the implementation of the system as it would add advantages to reduce energy consumption.

As highlighted in the options, all three proposals presented problems regarding the use of the exhaust wind, since there is no known system that makes it possible to reuse the potential. But in all the proposals there are possibilities for adjustments, as highlighted in green in the properties analyzed, with proposal number 3 being the most viable to apply where the system was to implement a pilot project in the exhaustion system of the cafeteria (R1) lighting the cold rooms. For this purpose, a feasibility study was carried out, ranging from the survey of needs, the elaboration of the project, sectorial approval, the preparation of the pilot project, the installation of the system, the appreciation of the results and the application of other system adjustment equipment. First, a prototype of the wind turbine was made, using deactivated parts and equipment, in prototype 1 a tower turbine, the exhaust pulley, the exhaust shaft and the generator were mounted, and in prototype 2 the 500w wind turbine, an exhaust fan was mounted. industrial system, a wind turbine fixing system with safety grilles, a panel installed with a battery system and the lighting 11 of the cold rooms powered by the equipment. Figure 7 shows a schematic of how prototypes are assembled.

As can be seen, the implementation of prototype 2 took into account the use of a wind turbine that was positioned in the exhaust duct whose installation followed a planned and executed pattern, figure 8 shows details of this implementation and highlights all aspects that support the viability of the system. Carvalho (2016) highlights that the feasibility of accommodating a wind system is very focused on the characteristics of the wind turbine, requiring a technical and economic analysis by the implementation team, as to the techniques related to the wind turbines, the performance and efficiency characteristics should be evaluated that satisfies the projections desired. Another important factor is the condition of the application site, the wind conditions, which must be rigorously calculated and measured to respond to environmental conditions, legislation and access to the electricity grid. The perception of these factors corroborates with the proposal that was implemented that sought to solve a problem by reusing a by-product of the activities in the factory. 
The application took place according to the elaboration in the work plan and the results are measured in figure 9, which shows the application condition and its variations. The application of the wind potential is attractive since having considered an investment with low it is observed that the established goals brought encouraging results, because when considering the nominal potential of the equipment, which was 500 watts and by technical variations, 460 watts is described, even thus, a generation of around $92 \%$ is perceived, which highlights that the system is viable and that the forms of insertion also contribute to the low release of polluting gases into the environment, in this case around $377 \mathrm{~kg}$ of CO 2 / year, however, there are many factors to align, not everything has turned into advantages. prioritize low energy consumption and that allows the reuse of a by-product that is generated in its use. It is, therefore, necessary to mitigate that the whole process took place in a thoughtful way for the production of low-cost alternative energy, where the results demonstrate the viability of the system, as long as its conditions and technical arrangements for sustainability for long periods are improved, the results were presented to the company in the form of technical reports demonstrating the pro and con factors of the applications, as detailed in the course of the work.

\section{Conclusion}

As an experimental activity and requiring arrangements for the execution of applications, it was very expensive to parameterize the points that were satisfactory for obtaining the results, but in the universe of sciences, wrong results also corroborate for improvement. In this study, this aspect was visible, as there were many technical barriers and the required adjustments required a lot of effort and applied thinking from the team. But with the results achieved, it became clear the feasibility of the proposal and that the application of a wind turbine in a system that reuses the winds of dissipating an activity generates savings and provides a service to the environment. So many processes that in their functionality waste materials for lack of the expertise of activities that overlap this discard that among other things, feeds the degradation of the planet, in this work it was possible to perceive the impact of the correct attitudes in macro systems and that, in a planned way can facilitate the reuse of waste materials such as gases, in the form of wind from exhaust fans, waste water from refrigerators, solid waste that is discarded in the environment without due care to impact. As a suggestion for new work, it would be important to carry out more impact studies on companies in different sectors that have their disposal materials made directly in the environment. As for the system that was tested in this study, studies should be carried out to improve the faults that were generated in the process and the optimization of the system for safe and suitable applications.

Acknowledgments: Thank God, who provided energy and benefits to complete this work.
Thank the classmates who participated in the requested research and activities. Finally, thank all the people who participated in another decisive stage of the course, thank you.

\section{REFERENCES}

BOFF587, Salete Oro; DA VEIGA, José Eli. Policies for Ecodevelopment: Integration between Technological Innovation in Renewable Energies and Sustainability. Law, Democracy and Sustainability. Southern College, p. 253, 2017.

BRASKEM.Wind energy (2019). Available at <https: // / energia-eolica-ja-ea-second-largest-source-energetica-dobrasil /> on 13.02. 2020.

CARVALHO, DDC of. Proposal for a Model for Implementation of Hybrid Systems for Wind and Photovoltaic Distributed Generation. 2016. Master's Dissertation. Brazil.

CAVALCANTI, Sthael Mariane Almeida. Application of the robust engineering method in a manual process of high temperature electrostatic painting. 2018.

COUTINHO, JRV, Melo, IC, Rocha, BM, de Freitas, DB, \& Assis Leandro Filho, F. Calculation of the natural frequency of wind turbine surface foundations. Revista Tecnologia, 40 (2), 2019.

ENERCONS .Wind Energy (2019). Available at $<$ http://www.enercons.com.br/noticias/546/os-10melhores-paises-do-mundo-em-capacity-de-energiaeolica $>$ accessed on 14.01.2020.

MORAES, Layse Freitas Boere. Modeling and Analysis of a Horizontal Shaft Wind Turbine Subject to the Action of Turbulent Winds. Campinas, SP, 2019. UNICAMP Master's Dissertation in Mechanical Engineering.

NETO, JDSB, Silva, LS, by Assis Leandro Filho, F., Rocha, BM, \& de Freitas, DB Numerical analysis of an aerodynamic profile using the OpenFOAM Platform. Revista Tecnologia, 38 (2), 2018.

OKITA, Willian Minoru. Numerical simulation of the aerodynamic performance of horizontal axis wind turbines. Campinas, SP, 2017. State University of Campinas Master's Dissertation in Mechanical Engineering.

SANTOS, Guilherme Martins dos.Analysis of a vertical axis wind turbine using the actuator cylinder method and computational fluid dynamics (CFD). 2018. Course Conclusion Paper. Federal Universityof Rio Grande do Norte.

SILVA, GFD, Silva, DPD, Silva, IPD, Silva, MSD, Bery, CCDSD, \& França, FRM Alternative energies: sustainable technologies for northeastern Brazil. Aracaju: Acad Association. of Intellectual Property, 2019. 